Sports Training

\title{
Crawl technique observation sheet for beginning swimmers: an evaluation proposal for swimming teachers
}

\author{
Jessica de Medeiros Vidal ${ }^{1}$ (D), Guilherme Tucher $^{1}$ (D), Leandro Nogueira ${ }^{1}$ (D), \\ Renato Cavalcanti Novaes ${ }^{2,4}$ (D), Rodrigo Gomes de Souza Vale ${ }^{2}$ (D), \\ Mariana Oliveira Rabelo de Castro $^{3}$ (D), Nathalia Glauss da Silva Medeiros ${ }^{1}$ (D), \\ Silvio de Cassio Costa Telles ${ }^{1,2}$ (iD \\ ${ }^{1}$ Universidade Federal do Rio de Janeiro, Escola de Educação Física e Desportos, Rio de \\ Janeiro, RJ, Brazil; ${ }^{2}$ Universidade do Estado do Rio de Janeiro, Instituto de Educação Física e \\ Desportos, Rio de Janeiro, RJ, Brazil; ${ }^{3}$ Universidade do Estado do Rio de Janeiro, Instituto de \\ Aplicação Fernando Rodrigues da Silveira, Rio de Janeiro, RJ, Brazil; ${ }^{4}$ Marinha do Brasil, Rio \\ de Janeiro, RJ, Brazil.
}

Associate Editor: Gustavo R. Mota, Universidade Federal do Triângulo Mineiro, Uberaba, MG, Brasil.

\begin{abstract}
Aims: This study aimed to present a technical evaluation proposal for the crawl stroke that can be used with large groups of swimmers, based on an observation sheet. Methods: Fifteen healthy university students aged between 18 and 30 years were chosen to participate in the study. The subjects were recorded swimming at a distance of 50 meters using the crawl technique at a comfortable and self-determined speed. The recordings simulated docent observation capacity. Five swimming teachers were selected to evaluate the proposed checklist and the subjects' technique. An observation sheet was created based on references present in literature containing ten items that are considered fundamental for swimming movements. The study was divided into (i) checklist validation, (ii) intra-evaluator consistency, and (iii) inter-evaluator consistency. Results: The proposed checklist fulfilled the validity criteria, with intraevaluator consistency varying between reasonable and substantial, with k varying between 0.36 and 0.73 respectively, while inter-evaluator consistency was deemed reasonable $(\mathrm{k}=0.24)$. Conclusion: According to the results that were obtained, the suggested list is valid and adequate for what it proposes to do.
\end{abstract}

Keywords swimming, evaluation, observation sheet, large groups, crawl technique.

\section{Introduction}

The vast amount of literature available regarding swimming technique evaluation in different circumstances demonstrates its relevance in learning and practicing swimming. ${ }^{1-5}$ However, many proposals require sophisticated equipment and a large amount of time for the testing and evaluation processes to occur and for the feedback to return to the swimmer and the teacher. Knudson and Morrison $^{6}$ suggest that the studies should involve simpler proposals, especially for beginners, which highlight the movement's basic characteristics. Nonetheless, aside from being scarce in the literature, evaluation proposals of this type mostly deal with adaptation to the water environment $^{7,8}$ and general abilities in the water. ${ }^{9}$ Furthermore, they are extensive, focused on non-essential characteristics, or are directed towards young high-performance swimmers. ${ }^{6,10,11}$ As such, little has been devised for beginning swimmers of various ages, whose swimming movement patterns require refinement.
On the other hand, qualitative analysis based on observation allows the teacher to evaluate their swimming students in real-time and almost immediately through an observation sheet, thus facilitating a more adequate intervention. ${ }^{6,12}$ The literature recognizes that qualitative evaluation is a more subjective method. ${ }^{10,12,13}$ However, due to its practicality, efforts must be made to improve it. A pathway to this improvement resides in the evaluation of a movement's fundamental characteristics - its most essential aspects- and not in its details.

Even so, despite the advances made by previous studies, ${ }^{1,10,11}$ we consider that their applicability in a swimming teacher's everyday activities with beginning swimmers is still limited. Nevertheless, we must emphasize that as the evaluation results are almost immediate, this allows the teacher to conduct many observations and evaluate large groups of swimmers, which is a common demand in gyms, universities, and basic education schools. 
The main objective of the present study consists in presenting a proposal for technical evaluation of the crawl swimming technique that can be used for large groups of swimmers, based on an observation sheet (i) with the swimming technique points validated in accordance with the essential movement characteristics for beginners, as well as tested for (ii) intra-evaluator and (iii) inter-evaluator usage consistency.

\section{Materials and Methods}

This project was approved by the Research Ethics Committee of the Pedro Ernesto University Hospital at Rio de Janeiro State University, under protocol number 82777317.3.0000.5259. Fifteen healthy university students between 18 and 30 years old with different experience levels in swimming and varying technical domain of the formal swimming styles participated in the study. The subjects swam 50 meters using the crawl technique at a comfortable, self-determined speed in a pool measuring 25 meters in length. Their swimming movements were recorded by the researcher, who accompanied the movement from a two-meter distance using a lateral and superior viewpoint, thus simulating docent observation capacity. The movements were recorded with a mobile phone from the South Korean manufacturer Samsung, model Galaxy Gran Prime Duos, which permits Full HD recordings with a resolution of $1920 \times 1080$ pixels.

In order to evaluate the checklist and the technique that was demonstrated by the subjects, this study included five swimming teachers with formal education and various experiences in the field (Table 1). It is important to note that this study is based on similar studies with ample citations in literature, such as those conducted by Corazza et al., 2006 ${ }^{11}$ and Madureira et al., 2008 ${ }^{1}$ which used, respectively, three and four evaluators. Furthermore, another highly commented study, conducted by Soares et al., $2001^{10}$ used only two evaluators. The inclusion criteria took into account their experience in teaching swimming, with a preference for those with greater academic educational experiences. All of those involved in the study (subjects and evaluators) received explanations about their

Table 1 - Evaluators' academic education level and swimming experience.

\begin{tabular}{lcc}
\hline Evaluator & Highest academic level & Swimming experience \\
\hline 1 & Master's degree & Teacher: 11 years; Coach: 4 years \\
2 & Doctorate & Teacher: 13 years; Coach: 9 \\
& years \\
3 & Bachelor's/Specializa- & Teacher: 8 years \\
tion & \\
5 & Master's degree & Teacher: 2 years \\
5 & Doctorate & Teacher: 8 years; Coach: 1 year \\
\hline
\end{tabular}

participation, contributed voluntarily, and had their questions answered.

An observation sheet for the crawl swimming technique, containing ten points considered essential in swimming movements, was created based on the descriptions and illustrations present in the literature. ${ }^{6,14}$ (Annex). In order to create a shortlist that is quick to use, thus fulfilling this study's goals, the choice was made to add the errors that the literature indicates as frequently recurrent. Each evaluated item is represented by an image that indicates the movement's correct execution and receives a score of one point and up to two possible mistakes, which receive zero points. The numerical information was used for statistical analysis. This medium was chosen as it permits quick and easy judgment of the movements.

\section{First part of the study: validation of the content of the crawl swimming technique observation sheet}

As suggested in the literature, the crawl technique observation sheet was analyzed in order to validate its content ${ }^{1,11,15,16}$. The evaluators examined the content, suggesting improvements to the list which was later readapted and reevaluated. The evaluative list was judged regarding its (i) clarity, (ii) technical pertinence, and (iii) applicability. The list was considered final when all of the criteria obtained the minimum classification of "adequate".

\section{Second part of the study: Intra-evaluator consistency}

The five evaluators analyzed the 15 subjects through the videos, using the observation sheet that was validated in the first part of this study and receiving the recommendation to (i) play each subject's video only once with no pauses and (ii) conduct the swimming component technique evaluation in the same order in which the points appear on the observation sheet, marking the image that best represented the gesture performed by the subject for the majority of the 50-meter trajectory. This initiative was adopted as it represents what a swimming teacher usually does in class. For the first evaluation (test), each evaluator had access to the videos through a link sent separately by e-mail in the proper order and with the subjects' distinct identifications. For the second evaluation, which occurred 15 days after the first one, a new email with a video access link was sent to the evaluators. There was no communication among the evaluators regarding the analyses on either occasion.

The Kappa Cohen coefficient $(\mathrm{k})$ was used in order to test intra-evaluator consistency. This coefficient shows that the observed consistency is not a coincidence. According to Landis and $\mathrm{Koch}^{17}$ the higher the values are, the higher the consistency is itself. Thus, the $\mathrm{k}$ value can be considered "poor" when $\mathrm{k}$ is lower than 0 ; When $\mathrm{k}$ is between 0 and 0.20 , consistency is "slight"; It is "reasonable" when $\mathrm{k}$ is between 0.21 and 0.40 and "moderate" 
when k varies between 0.41 and 0.60 ; As for the "substantial" level of consistency, it is achieved when $\mathrm{k}$ is between 0.61 and 0.80 . A $\mathrm{k}$ value between 0.81 and 1.00 shows "almost perfect" consistency, guaranteeing that the findings possess the highest level of trustworthiness ${ }^{17}$. Based on the result of qualitative human movement evaluation studies, ${ }^{6,18}$ a k coefficient of at least 0.41 is considered acceptable; that is, the intra-evaluator consistency must be considered at least moderate. The Kappa Cohen coefficient (k) was determined on SPSS software, version 24. A statistical significance value of $\mathrm{p}<0.05$ was adopted. Intra-evaluator consistency was measured for all evaluators. However, the ones that achieved the best and worst results were excluded from the study in order to concentrate the results and guarantee a higher degree of solidity.

\section{Third part of the study: inter-evaluator consistency}

Consistency among evaluators was tested through the retest data from the three evaluators who participated in the second part of this study. The retest data was chosen considering the possible occurrence of the learning effect on the checklist usage, favoring the obtention of more consistent results. Fleiss' Kappa for multiple evaluators ${ }^{19}$ was used to test the consistency on Microsoft Excel 2013 software. Also, the Kappa (k) consistency levels were the same as those adopted during the second part of the study, with an acceptable k-value being at least 0.41 ; For statistical significance, the value $p<0.05$ and a $95 \%$ confidence interval for $\mathrm{k}$ were adopted.

\section{Results}

First part of the study: validation of the content of the crawl swimming technique observation sheet

Regarding content description clarity on the observation sheet, three evaluators considered it very easy to understand and two deemed it easy to understand; 4 evaluators rated the technical pertinence of the movements present on the sheet as very adequate and one judged it adequate. Regarding the observation sheet's applicability, two evaluators considered it to be very viable and three saw it as viable (Table 2). The evaluators gave suggestions about (i) improvements for the items' technical representation, (ii) nomenclature usage, (iii) the viability of visualizing items pertaining to the sub-aquatic stage, and (iv) the need for previous knowledge of the sheet in order to better use it.

\section{Second part of the study: Intra-evaluator consistency}

Table 3 presents the intra-evaluator consistency results, which varied from reasonable ( $\mathrm{k}$ between 0.21 and 0.40 ) to substantial ( $\mathrm{k}$ between 0.61 and 0.80 ). Evaluators
Table 2 - Result in the number of evaluators of the content analysis pertaining to the content description clarity, the technical pertinence of the movements, and the applicability of the lists.

\begin{tabular}{lr}
\hline Clarity of list content description & 3 \\
\hline Very easy to understand & 2 \\
Easy to understand & \\
Difficult to understand & 4 \\
Very difficult to understand & 1 \\
Technical pertinence of the movements on the lists. & \\
Very adequate & \\
Adequate & 2 \\
Not very adequate & 3 \\
Inadequate & \\
List applicability & \\
Highly viable & \\
Viable & \\
Not very viable & \\
Unviable & \\
\hline
\end{tabular}

Table 3 - Intra-evaluator consistency for the items proposed on the crawl swimming technique observation sheet.

\begin{tabular}{lcc}
\hline Evaluator & $\mathbf{k}$ & Consistency classification \\
\hline 1 & $0,73(\mathrm{p}<0,01)$ & Substantial \\
3 & $0,59(\mathrm{p}<0,01)$ & Moderate \\
5 & $0,36(\mathrm{p}<0,01)$ & Reasonable \\
\hline
\end{tabular}

2 and 4 were excluded due to their respective positions of best and worst intra-evaluator consistency.

\section{Third part of the study: Inter-evaluator consistency}

Table 4 shows the inter-evaluator consistency (in pairs), the percentage of general inter-evaluator consistency, and the general inter-evaluator consistency classification, as well as the $95 \%$ confidence interval.

\section{Discussion}

Although shorter distances are also adequate for evaluating beginning swimmers or those who are in poor

Table 4 - Inter-evaluator consistency for the items proposed on the crawl swimming technique observation sheet.

\begin{tabular}{lcc}
\hline Criterion & $\mathbf{k}$ & Consistency classification \\
\hline Evaluators 1 and 3 & $0,41^{*}$ & Moderate \\
Evaluators 1 and 5 & $0,20^{*}$ & Light \\
Evaluators 3 and 5 & $0,19^{*}$ & Light \\
$\%$ of general consistency & 72,89 & - \\
General consistency & 0,24 & Reasonable \\
95\% confidence interval & $0,09-0,39$ & Light to reasonable \\
\hline${ }^{*} \mathrm{p} \leq 0,01$. & &
\end{tabular}


physical shape as shown in other studies that opted to evaluate swimmers in 10-to-15-meter distances ${ }^{1,10}$, the 50 -meter distance used in the present study is also valid. This optimizes the evaluation of technique maintenance and consistency in beginning swimmers. This proposal is different from the methods used in other studies since, if tiredness causes a reduction in movement quality throughout the test, this should be considered in the evaluation. Each proposal demonstrates its limitations and possibilities, and the teachers must choose that which they believe most adequate to evaluate their beginner swimming students.

Despite achieving satisfactory results, the study has some limitations. For example, the evaluators mentioned that some of the figures shown in the checklist are not represented in the same observation plane that was used in the videos used for the analysis. This occurred due to the graphic limitations present in the checklist's creation. Some of the figures were difficult to represent and, at other times, the limitations themselves made the figures unclear, impairing the identification of the points that needed to be evaluated. Thus, the illustrations were created at different angles from those shown in the videos in order to make the checklist points clearer. Another limitation that was pointed out has to do with visualizing the subjects on video screens, not permitting the evaluator to move in order to attain a better angle to verify certain movements, such as in the points that show underwater movements or those that are stopped by the refraction phenomenon. It is interesting to note that this limitation is imposed by the instrument's chosen validation method, which uses videos in order to obtain executions that show no technical difference between the test and retest moments, which could have occurred if the subjects needed to be observed in real-time at two different moments. This type of problem can be easily resolved since the intention is that this checklist is used personally.

Through the data pertaining to the three parts of the present study, we verified that the proposal fulfilled the validity criteria, intra-evaluator consistency varied from reasonable to substantial, and general inter-evaluator consistency was shown to be reasonable. At the end of the evaluations, all of the evaluators were consulted regarding their following of the previously established instructions. All evaluators confirmed following the instructions and it is important to point out that there were no discrepancies in their answers that would cause doubt regarding their compliance. The qualitative analysis sheet for crawl technique evaluation in beginning swimmers fulfilled the validity criteria required in the literature and demonstrated parameters that are close to those present in previously cited studies such as, for instance, Madureira et al., ${ }^{1}$ who, upon analyzing the list's content obtained, as results, satisfactory technical clarity, and pertinence, as well as good applicability. This is also similar to the study conducted by
Corazza et al., ${ }^{11}$ who obtained unanimity in the opinion of the four evaluators regarding the suggested instrument's clarity and applicability. Thus, we believe that the sheet content is satisfactorily clear, appropriately pertinent, and adequately applicable for the proposed analysis.

The intra and inter-evaluator consistency values shown in the mentioned studies were superior to those found by this study, although it is important to point out the difference in the method used by the authors to test for consistency and even the type of movement that was evaluated. In Madureira et al., ${ }^{1}$ the authors indicated the main movement errors they considered possible in swimming, even going to the point of distinguishing the movements of the right and left sides. From the observed errors, the athletes would receive a score for each of the 12 proposed items, which was the sum of the scores from their subitems. As such, we understand that consistency for the item was facilitated as the score could be the same or even of a similar value, despite possible differences in the subitem scores.

It is also important to highlight that the method used by Madureira et al. ${ }^{1}$ permitted the use of specific movement analysis software. The videos showed the movements from outside and inside the water and the evaluators had the option of viewing the videos as many times as necessary, as also proposed by Junior ${ }^{15}$ and Magarotto Junior and Deprá. ${ }^{16}$ We recognize the relevance of this method, though our proposal aimed for a scenario closer to that which is commonly encountered by teachers in their classes. Thus, the teacher should observe the swimmers from a certain distance, only from above the water, and, in this manner, judge the quality of their movements.

Soares et al. ${ }^{10}$ used a method that showed two observation planes (frontal and lateral) and looked for specific details and movement errors made by the competitive swimmers that were evaluated. Due to these characteristics, the evaluative instrument appears to be inadequate for evaluating beginning swimmers, such as the ones analyzed in the present study, since these subjects still execute the fundamental movement characteristics incorrectly. The proposal from Soares et al. ${ }^{10}$ and this study's proposal were made for distinct groups. Since the current study's observation sheet was constructed for beginning swimmers, the aim is to indicate the movement from a higher observation plane, focusing on the fundamental characteristics, without worrying about the details which would, perhaps, be more important in improving movements in more experienced swimmers.

For a proper technical evaluation of the crawl swimming technique, as well as for an adequate qualitative analysis of human movement, the considerations that are present in the literature must be taken into account. The first is that a correct movement must not be understood as something rigid, unique, and unchangeable. Thus, from its essential characteristics, it is necessary to understand and 
allow a certain latitude for performance within the desired spectrum that may be considered adequate. From this, the second discussion point comes up, which is that of the importance of knowing the executor's characteristics, since the latitude for performing the movement correctly must be adapted to each individual's differences and limitations. $^{6}$

The third matter refers to the discussion of observation criteria among the evaluators. Despite adequate movement allowing for variation within that which is considered ideal, this perception of latitude varies among the evaluators, ${ }^{13}$ which means that the movement evaluation is based on different standards. Thus, in this study, it was determined that there should be prior communication among the evaluators in order to set observation and evaluation criteria. From these three points of discussion, it is possible to understand that: adequate movement allows for some latitude in execution; this may happen due to individual characteristics and is not an error. The evaluators must have a prior discussion regarding which observation and evaluation criteria they will use, which may make the intra and inter-evaluator consistency criteria more adequate, which in turn can generate reflections for new studies.

\section{Conclusion}

The proposed observation sheet for qualitative evaluation of the crawl swimming technique fulfilled the validity criteria, intra-evaluator consistency varied from reasonable to substantial, and general inter-evaluator consistency was reasonable. Despite two evaluators demonstrating intra-evaluator consistency above the requirements for the present study, the inter-evaluator consistency did not fulfill the established requirements for most cases. Either way, these criteria remained within the parameters set in the literature for qualitative evaluation of human movement, which permitted the use of the proposed observation sheet. A preparation stage before the evaluation that involves discussing the subject as well as a discussion among the evaluators about the observation criteria may bring about superior consistency rates.

The present study offers yet another possibility of evaluation, which can be conducted in less time, with large numbers of swimmers and offers a physical report that can be easily shown to the students, their parents, and the institution. Moreover, all tests can be filmed, which can also provide video feedback, fostering motor learning, motivation, and self-assessment. ${ }^{20,21,22}$ Although the methods use more sophisticated filming techniques may be more precise and detailed, the current proposal aimed to offer an instrument that could be used in a teacher's daily activities, facilitating feedback and stimulating the teaching-learning process.

\section{References}

1. Madureira F, Gollegã DG, Rodrigues HF, De Oliveira TAC, Dubas JP, Freudenheim AM. Validação de um instrumento para avaliação qualitativa do nado "Crawl". Rev Bras Educ Fís e Esporte. 2008;22(4):273-84.

2. McCabe CB, Sanders RH, Psycharakis SG. Upper Limb Kinematic Differences Between Breathing and Non-breathing Conditions in Front Crawl Sprint Swimming. J Biomechanics. 2015;48(15):3995-4001.

3. Narita K, Nakashima M, Takagi H. Effect of leg kick on active drag in front-crawl swimming: Comparison of the whole stroke and arms-only stroke during front-crawl and the streamlined position. J Biomechanics. 2018;76:197-203.

4. Schmidt R, Wrisberg C. Motor learning and performance: A situation-based learning approach. Ed. Champaign, Human Kinetics, 2008.

5. Tsunokawa T, Tsuno T, Mankyu H, Takagi H, Ogita F. The Effect of Paddles on Pressure and Force Generation at the Hand during Front Crawl. Human Mov Sci. 2018;57:40916.

6. Knudson D, Morrison CS. Qualitative Analysis of Human Movement. Ed. Champaign, Human Kinetics, 2002.

7. Wizer R, Franken M, Castro FADS. Concordância intra e inter-observador de protocolo de avaliação de habilidades aquáticas de crianças. Rev Bras Ciência e Movimento. 2016;24(1):101-7.

8. Esteves CM. Adaptação ao meio aquático: determinar o grau de aquisição das competências de adaptação ao meio aquático de crianças na educação pré-escolar, em contextos de ensino com diferentes profundidades da piscina. Coimbra. Dissertação [Mestrado em Jogo e Motricidade na infância] - "Instituto Politécnico de Coimbra"; 2018.

9. Varveri D, Flouris A, Smirnios N, Elisana P. Developing and Testing an Instrument to Assess Aquaticity in Humans. J Bodyw Mov Ther. 2016;20(3):497-503.

10. Soares S, Fernandes RJ, Carmo CM, Silva JVS, Vilas-Boas JP. Avaliação qualitativa da técnica em natação: apreciação da consistência de resultados produzidos por avaliadores com experiência e formação similares. Rev Port Ciências do Desporto. 2001;1(3):22-32.

11. Corazza, ST, Pereira, E, Villis, JMC, Katzer, JI. Criação e validação de um teste para medir o desempenho motor do nado crawl. Rev Bras Cineantropom Desempenho Hum. 2006;8(3):73-8.

12. Lees A. Technique Analysis in Sports: A Critical Review. J Sports Scie. 2002;20(10):813-28.

13. Mendes R, Clemente FM, Rocha R. Damásio AS. Observação como instrumento no processo de avaliação em educação física. Exedra J. 2012;6:57-69.

14. Maglischo EW. Swimming Fastest: The essential reference in technique, training, and program designs. Ed. Champaign, Human Kinetics, 2003.

15. Junior CDMM. Validação de uma lista de checagem para análise qualitativa do saque do voleibol. Motriz: J Phys Educ. 2003;9(3):153-60.

16. Junior LAM, Deprá PP. Validação de lista para análise qualitativa da recepção no voleibol. Motriz: J Phys Educ. 2010;16(3):571-9. 
17. Landis JR, Koch GG. The Measurement of Observer Agreement for Categorical Data. Biometrics. 1977;33 (1):159-74.

18. Safrit M, Wood J. Measurement concepts in physical education and exercise science. Ed. Champaign, Human Kinetics, 1989.

19. Fleiss JL. Measuring nominal scale agreement among many raters. Psychological bulletin. 1971;76(5):378-82.

20. Weir T, Connor S. The Use of Digital Video in Physical Education. Technology, Pedagogy, and Education. 2009;18 (2): $165-71$.

21. Avila L, Chiviacowsky S, Wulf G, Lewthwaite R. Positive social comparative feedback enhances motor learning in children. Psychol Sport Exerc. 2012;13(6):849-53.

22. Potdevin F, Vors O, Huchez A, Lamour M, Davids K, Schnitzler C. How can video feedback be used in physical education to support novice learning in gymnastics? Effects on motor learning, self-assessment, and motivation. Physical Educ Sport Pedagogy. 2018;23(6):559-74.

\section{Annex}

Figure 1. Crawl technique observation sheet for beginning swimmers 1.
Figure 2. Crawl technique observation sheet for beginning swimmers 2.

\section{Corresponding author}

Silvio de Cassio Costa Telles, Universidade do Estado do Rio de Janeiro, Instituto de Educação Física e Desportos, Rua São Francisco Xavier, 524. $9^{\circ}$ andar, Bloco F., 20550900, Rio de Janeiro, RJ, Brazil.

E-mail: telles.ntg@terra.com.br.

Manuscript received on September 15, 2020

Manuscript accepted on February 23, 2021

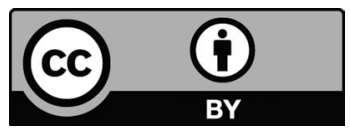

Motriz. The Journal of Physical Education. UNESP. Rio Claro, SP, Brazil - eISSN: 1980-6574 - under a license Creative Commons - Version 4.0 